\title{
Medical Home Transformation in Pediatric Primary Care-What Drives Change?
}

Jeanne W. McAllister, BSN, MS,

$M H A^{1}$

W. Carl Cooley, $M D^{1}$

Jeanne Van Cleave, $M D^{2}$

Alexy Arauz Boudreau, $M D^{2}$

Karen Kublthau, $P b D^{2}$

${ }^{1}$ Center for Medical Home Improvement, Crotched Mountain Foundation, Concord, New Hampshire

${ }^{2}$ Center for Child \& Adolescent Health Research and Policy, Massachusetts General Hospital, Boston, Massachusetts

Conflict of interest: authors report none.

\section{CORRESPONDING AUTHOR}

Jeanne W. McAllister, MHA

Center for Medical Home Improvement

Crotched Mountain Foundation

8 Low Ave, Ste 1

Concord, NH 03301

mcallisterjeanne3@gmail.com

\begin{abstract}
PURPOSE The aim of this study was to characterize essential factors to the medical home transformation of high-performing pediatric primary care practices 6 to 7 years after their participation in a national medical home learning collaborative.

METHODS We evaluated the 12 primary care practice teams having the highest Medical Home Index (MHI) scores after participation in a national medical home learning collaborative with current $\mathrm{MHI}$ scores, a clinician staff questionnaire (assessing adaptive reserve), and semistructured interviews. We reviewed factors that emerged from interviews and analyzed domains and subdomains for their agreement with $\mathrm{MHI}$ and adaptive reserve domains and subthemes using a process of triangulation.
\end{abstract}

RESULTS At 6 to 7 years after learning collaborative participation, 4 essential medical home attributes emerged as drivers of transformation: (1) a culture of quality improvement, (2) family-centered care with parents as improvement partners, (3) team-based care, and (4) care coordination. These high-performing practices developed comprehensive, family-centered, planned care processes including flexible access options, population approaches, and shared care plans. Eleven practices evolved to employ care coordinators. Family satisfaction appeared to stem from better access, care, and safety, and having a strong relationship with their health care team. Physician and staff satisfaction was high even while leadership activities strained personal time.

CONCLUSIONS Participation in a medical home learning collaborative stimulated, but did not complete, medical home changes in 12 pediatric practices. Medical home transformation required continuous development, ongoing quality improvement, family partnership skills, an attitude of teamwork, and strong care coordination functions.

Ann Fam Ann 2013;11:S90-S98. doi:10.1370/afm.1528.

\section{INTRODUCTION}

7 he patient- and family-centered medical home grounds US Maternal and Child Health Bureau policy and represents a strategic priority of the American Academy of Pediatrics. ${ }^{1,2}$ The Academy states that all children deserve a medical home-a source of accessible, continuous, comprehensive, family-centered, coordinated, compassionate, and culturally effective care. To date, little is known, however, about enablers of successful medical home change and whether quality improvement (QI) is an essential tool for transformation. ${ }^{3}$ We studied 12 practices showing high performance after their participation in a QI learning collaborative to characterize attributes of transformed pediatric medical homes.

\section{METHODS}

In 2003, the Center for Medical Home Improvement and the National Initiative for Children's Healthcare Quality conducted 2 year-long, nationally based learning collaboratives to foster implementation of the medical 
home model for children and youth with special health care needs. ${ }^{4}$ Forty-five practice teams participated.

Teams consisted of a pediatric physician champion, 2 "parent partners," and, optionally, a care coordinator. They completed the validated Medical Home Index $(\mathrm{MHI})^{5}$ before and after learning collaborative participation (data points 1 and 2). Core components of the learning collaborative included the Chronic Care Model translated for pediatrics as the Care Model for Child Health in a Medical Home, which promotes a team approach to population care and family-centered care coordination. ${ }^{6,7}$

\section{Sample}

We used a modified positive deviance approach to select 15 high-performing practices from 2 collaborative cohorts based on postcollaborative MHI scores at the end of the collaboration. ${ }^{8}$ Of the 15 invited, 2 had lost their physician champion and 1 was unable to gain administrative approval; thus, 12 practices agreed to participate. The geographic distribution, urban-rural location, and practice type of the studied and nonstudied sites did not differ. Research funding allowed for 15 practices with no retrospective comparison. To further verify practice quality, we collected additional data in 6 practices with the highest MHI scores. We performed pediatric quality care audits of patient charts and administered the Modified Consumer Assessment of Healthcare Providers and Systems Health Plan Survey 4.0 Version: Child Medicaid Questionnaires (CAHPS) to assess the family perspective..$^{9-12}$

Crotched Mountain Foundation's institutional review board approved the study.

\section{Data Collection}

We used a mixed methods approach incorporating 3 primary data sources - the MHI, a clinician staff questionnaire, and semistructured interviews — in each of the 12 practices, as described below. The study tools used are available online (http://www.medicalhomeimprovement.org).

\section{Medical Home Index}

Each practice completed a current $\mathrm{MHI}$ assessment in 2010, 6 to 7 years after participation in the learning collaborative (data point 3 ). The MHI assesses 25 indicators of medical "homeness" organized under 6 practice domains: organizational capacity, chronic condition management, care coordination, community outreach, data management, and quality improvement. Indicators are measured across 4 levels of achievement: level 1 represents basic care level 2, responsive care, level 3, proactive care; and level 4, comprehensive care. An 8-point Likert scale measures structures and processes across these levels; results are reported as domain mean scores, and total $\mathrm{MHI}$ scores are expressed as a percentage of a maximum of 100 . Higher values indicate greater levels of the attribute.

\section{Clinician Staff Questionnaire}

The clinician staff questionnaire was completed by the physician champion and the care coordinator or staff member. ${ }^{13}$ We added a question to this questionnaire to measure adaptive reserve, the team's ability to make and sustain change. Twenty-three items address QI, teamwork, and problem solving using a 5-point Likert scale. We converted total mean scores to a 100 -point scale to allow comparison with MHI scores. Higher values indicate greater levels of the attribute.

\section{Semistructured Interviews}

Two researchers conducted semistructured interviews at each of the 12 practices between November 2010 and May 2011. Interviews were conducted individually with the physician champion, 2 parent partners having children with special health care needs, and a care coordinator. Interviewees were original learning collaborative team members or someone currently in their role. All physician champions were previous collaborative participants. If original parent partners were unavailable, parents currently involved with medical home QI effort were invited, as occurred in a single practice. Coordinators interviewed were current staff.

The focus of interviews was to identify factors that facilitated adoption of the medical home model, and understand its impact on the practice, children, and families. Questions were designed to assess factors that enabled medical home improvements; characteristics that currently made the practice a strong medical home; and impact of the medical home on parents, children, clinicians, and staff.

\section{Data Management}

$\mathrm{MHI}$ and adaptive reserve scores were electronically reported to the Center for Medical Home Improvement's secure database; confidential results were password protected and accessible only to the research team. Interviews were recorded, transcribed, and entered into NVivo software version 9.0 (QSR International Pty Ltd) and held securely by the Center for Adolescent Research and Policy at Massachusetts General Hospital.

\section{Analysis}

We used a deductive approach to analyze the interview data. We applied a coding scheme developed by study authors having prior understanding of medical home innovations. 5,14-17 Coding domains included (1) helpfulness of the original medical home learning collabora- 
tive, (2) key internal and external factors affecting transformative change, (3) key medical home manifestations in practice, and (4) impact on children, families, and practices. We added subdomain factors when new concepts emerged.

We considered coding factors consistently as to whether they presented barriers to or facilitators of improvement, but rejected that approach because factors proved to be more nuanced. Initial coding therefore simply captured the presence of a factor; valance was addressed and integrated across themes and attributes. We attempted to capture the dominant views and values of interviewees while discussing alternative perspectives.

All authors participated in interviewing; 2 authors coded interviews from each practice. We analyzed adaptive reserve for physician champions and coordinators as total mean scores and as uncoupled individual scores, allowing for comparison. Interview coding intensity was examined for emphasis of emergent themes. We reviewed coding domains and subdomains, and analyzed them for their agreement with $\mathrm{MHI}$ and adaptive reserve subthemes. This strategy allowed for the triangulation of the $\mathrm{MHI}$ and adaptive reserve to dominant qualitative interview domains. ${ }^{18}$

\section{RESULTS}

\section{Practice Characteristics}

Characteristics of the practices 6 to 7 years after their participation in the national medical home learning collaborative are shown in Table 1. The practices were diverse. One-third did not have any source of supplemental support for medical home initiatives.

\section{Quantitative Results}

Figure 1 shows the practices' total, transformed MHI scores at the precollaborative, postcollaborative, and current (2010) time points. Scores had improved from baseline by $21 \%$ at the end of the collaborative. Furthermore, scores improved an additional 13\% from the postcollaborative time point to the current time point. The greatest improvement was seen in the domains of care coordination and chronic condition management, followed by the QI domain.

Figure 1 also shows the practices' adaptive reserve scores (transformed to a 100 -point scale) in relationship to their MHI scores. The adaptive reserve total mean score of 75.0 was correlated with the current $\mathrm{MHI}$ total scores (Pearson coefficient $=0.867$ ). Adaptive reserve was higher for physicians than coordinators for perceived time for improvement, professional growth, and teamwork. Care coordinators scored higher for learning from mistakes.

\section{Qualitative Results}

Table 2 summarizes the interview data analyzed according to our coding scheme, counted quotes, and factor emphasis. A total of 7,302 interview quotes were counted and coded. Interrater reliability was good with $\kappa$ scores ranging from 0.81 to 0.94 (physi-

\section{Table 1. Practice Characteristics}

\begin{tabular}{|c|c|c|c|c|c|}
\hline Practice & $\begin{array}{c}\text { Years } \\
\text { Since } \\
\text { MHLC }\end{array}$ & Location & Practice Type & Ownership & Patients, Visits per Year, No. \\
\hline 1 & 7 & Mountain state & Academic continuity clinic & Academic & 4,000 visits \\
\hline 2 & 7 & Mountain state & Private, rural, small (2 clinicians) & Independent, small & 528 patients, 2,000 visits \\
\hline 3 & 6 & Mid Atlantic & $\begin{array}{l}\text { Multispecialist network, subur- } \\
\text { ban, urban }\end{array}$ & Hospital owned & 22,500 patients \\
\hline 4 & 7 & Northeast & Academic medical center & Hospital owned & 6,790 visits \\
\hline 5 & 7 & Mountain state & Network, suburban and rural & Hospital owned & 13,511 patients \\
\hline 6 & 6 & Midwest & Private, suburban & Independent, large & 12,000 patients, 7,000 visits \\
\hline 7 & 7 & Midwest & Private, suburban & Independent, large & 13,000 patients \\
\hline 8 & 6 & South central & $\begin{array}{l}\text { Community health center, } \\
\text { Hispanic }\end{array}$ & $\begin{array}{l}\text { Community health center } \\
\text { (FQHC) }\end{array}$ & 13,410 patients \\
\hline 9 & 7 & Midwest & Integrated network, urban & Hospital owned and based & 4,600 visits \\
\hline 10 & 7 & Mid Atlantic & Suburban network & Hospital owned & 6,000 visits \\
\hline 11 & 7 & Mid Atlantic & Private, suburban, multisite & Independent, large & 12,000 patients \\
\hline 12 & 6 & Midwest & Network, suburban & Hospital owned & 27,597 patients \\
\hline
\end{tabular}


cian champions), 0.81 to 0.95 (care coordinators), and 0.88 to 0.96 (parent partners). The thematic findings are described below, with some examples of comments by interviewees.

\section{Quality Improvement}

Physicians benefited from peer-based learning, identifying the learning collaborative as "what got them started" using an ongoing QI process. Eleven of 12 practices developed formalized QI team processes including active parent partner participation. All expressed the need for standards and structures to guide their improvement efforts, and time for reflection and planning. They viewed their QI processes as crucial, but indicated that substantial personal time and working on multiple fronts were required to make headway.

I think medical home is a process. I don't think it's an endpoint, it's constantly evolving; if you get one thing going, there's always something else you can improve upon. QI should be a way of practice life (physician champion, practice 6).

\section{Family-Centered Care}

Family-centered care was a theme supported by all 3 primary data sources. The MHI specifically inquires about staff understanding and applying family-centered concepts; $75 \%$ responded that they had "full knowledge and regularly applied family-centered concepts."

Adaptive reserve does not address family centeredness, but we added a relevant statement to the questionnaire: "Youth/family involvement in planning and quality improvement is routinely valued and practiced here." The mean score for this statement was $80 \%$, reflecting strong agreement. Interview data supported how practice teams valued parent partner participation.

Parent partners told their stories, expressed goals and needs, suggested changes, and shared community resources; all benefited. Physician champions found this parental involvement motivating but acknowledged that the recruitment, orientation, and engagement of parent partners were difficult. Most parent partners still used the practice for care and helped with QI efforts. One example shows how parents contributed to team learning:

There was that independence piece for my daughter. She's going to have to do this all her life. So we talked with our medical home team. We needed to work on her independence, starting with checking herself in for appointments. I helped with the training, and the front desk was very good about letting her act for herself at future visits (parent partner, practice 6).

\section{Team-Based Care}

Team-based care is a concept integrated across the $\mathrm{MHI}$, higher scores reflect stronger team qualities. The adaptive reserve mean score of $75 \%$ suggests a high level of team-based communication/collaboration, representing a combined ability to make, tolerate, and sustain change. Teamwork and attitude were emphasized in interviews as energizing and critical to quality. Interviewees described the spread of teamwork across clinicians and staff.

It starts as the family walks off that elevator. Everybodypatients and staff — understand that this is a medical home. Teamwork really drives the whole concept; everyone is involved from every level (care coordinator, practice 4).

I have a partner in the complex care of my child, the team here, they have our backs (parent partner, practice 9).

\section{Care Coordination}

For the $6 \mathrm{MHI}$ indicators in the care coordination domain, mean scores nearly doubled from before the collaboration (3.82) to after the collaboration (6.39), demonstrating an improvement. Adaptive reserve scores reflect the combined achievement of clinicians and coordinators. Almost one-half of coded domains and subdomains, or 3,429 of them, were related to coordination, $59 \%$ of these domains/subdomains were associated with team-based, planned, coordinated care. Care plans developed in partnership with families were attributed with outcomes including safety, reliability, and reduced wastefulness.

At the onset of the collaborative, none of the 12 practices had a coordinator position; by 2011, all but 
Figure 1. $\mathrm{MHI}$ scores for the practices at 3 points in time and adaptive reserve $(\mathrm{N}=12)$.

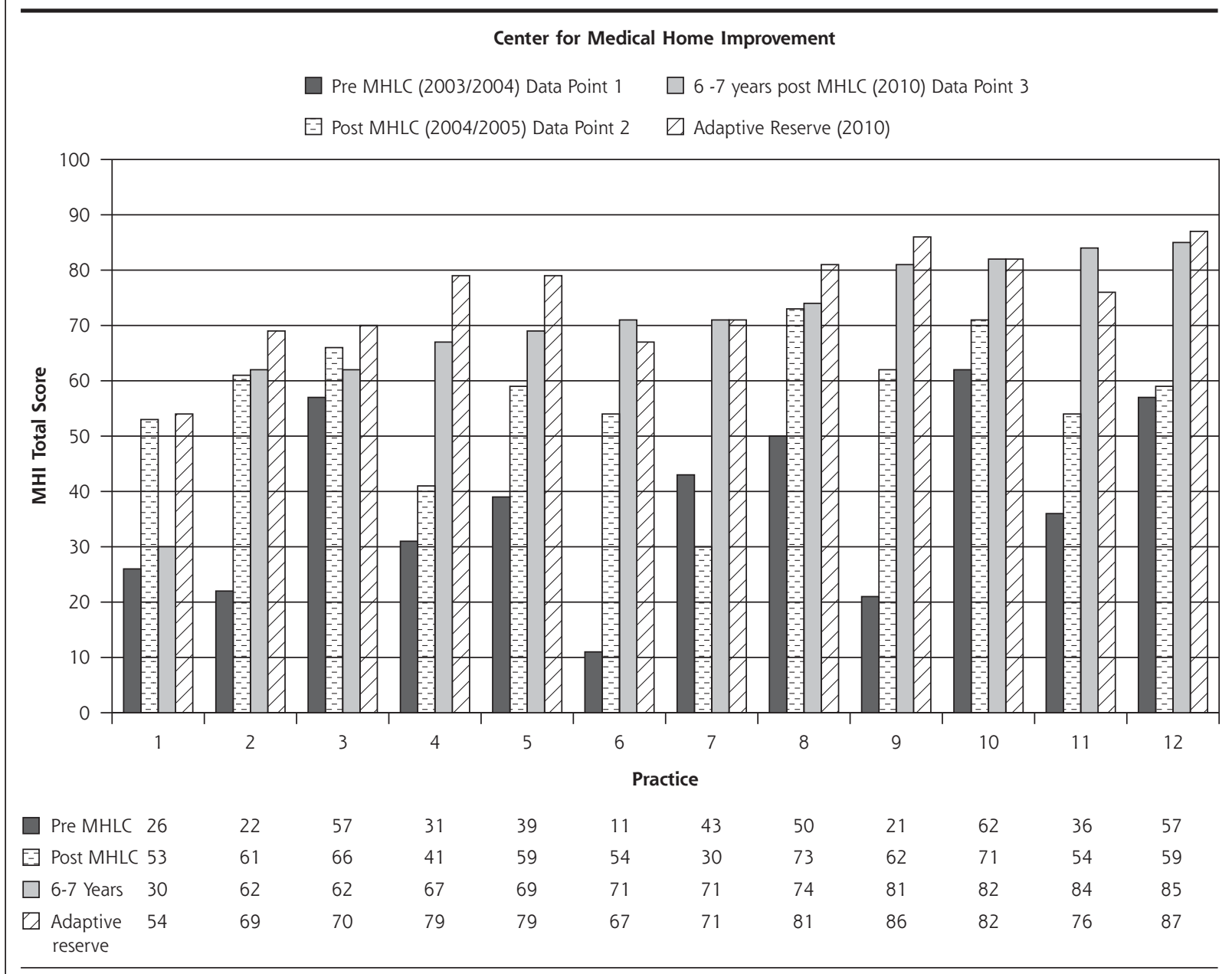

$\mathrm{MHI}=$ Medical Home Index $\mathrm{MHLC}=$ Medical Home Learning Collaborative.

Note: Total MHI scores are expressed as a percentage of a maximum of 100; higher values indicate greater levels of "homeness." Adaptive reserve scores are expressed on a 100-point scale, with higher scores indicating greater reserve. The MHI and adaptive reserve scores were correlated (Pearson coefficient $=0.867$ ).

the smallest practice supported this position within their budget, with external grant funding, or both. Adding the role of care coordinator increased capacity to be proactive, support families, and reach out to communities. Physicians said they would "not go back" to their previous care model.

Coordination of care, using care plans, is amazingly effective. We have a well-child visit and create a care plan; then 6 months later hold a chronic care visit, it's like the problems melt away; unplanned hospitalizations tend to go away (physician champion, practice 12).

We saved that family unnecessary visits and tests - that was a result of having a coordinator to help right the ship a little bit (physician champion, practice 4).

Care coordination support is so helpful; it is all I would do. Our family has benefited, I can be a parent (parent partner, practice 2).

\section{Care Quality and Satisfaction}

Parents whose children live with chronic conditions described having a "second home" and "trusting relationship" with their care team. Inclusion as "partners" demonstrated professional respect of the parent viewpoint and of their major role in their child's life. As one noted, "This practice is my lifeline" (parent partner, practice 7 ).

Practices reported important care improvements tailored to complex patients, but also described how their efforts stretched to improve preventive and acute care for all children/youth.

I would have told you in the beginning that the medical home was coordination for kids with special needs; making a smooth transition from medical home to specialist; making sure they have medical information when hospitalized; receiving follow-up care. But a medical home is ensuring children who need well-child checks, good access to care 


\section{Table 2. Semistructured Interview Domains and Top Subdomains}

\begin{tabular}{|c|c|c|c|}
\hline $\begin{array}{l}\text { Domain and Subdomain; Items Coded, } \\
\text { No. }(\%)^{a}\end{array}$ & $\begin{array}{l}\text { Subdomain } \\
\text { Coding } \\
\text { Density }\end{array}$ & Subdomain Item & $\begin{array}{l}\text { Essential Medical } \\
\text { Home Attribute(s) } \\
\text { Supported }^{b}\end{array}$ \\
\hline \multicolumn{4}{|l|}{ Medical Home Learning Collaborative; 223 (3) } \\
\hline \multirow{3}{*}{$\begin{array}{l}\text { In what way was the Medical Home Learning Collab- } \\
\text { orative helpful?c }\end{array}$} & 57 & Provided information/tools/measures & QI \\
\hline & 47 & Family participation built in & FCC \\
\hline & 47 & $\begin{array}{l}\text { Provided structure and standards for the } \\
\text { transformation effort }\end{array}$ & Q। \\
\hline \multicolumn{4}{|l|}{ Drivers/barriers for practice transformationd; 2,850 (39) } \\
\hline \multirow{7}{*}{$\begin{array}{l}\text { Key internal/external factors that help/hurt a practice } \\
\text { transform to a medical home? }\end{array}$} & 516 & Ability to be reimbursed & - \\
\hline & 352 & Leadership & QI \\
\hline & 324 & Patient collaboration/encouragement & FCC \\
\hline & 268 & $\begin{array}{l}\text { Practice environment/extended environ- } \\
\text { ment (eg, hospital linked to practice) }\end{array}$ & - \\
\hline & 244 & Staff capacity & TBC \\
\hline & 208 & An electronic health record & - \\
\hline & 143 & Gained time for innovation and reflection & QI, TBC \\
\hline \multicolumn{4}{|l|}{ Medical home characteristicse; 3,429 (47) } \\
\hline \multirow[t]{7}{*}{$\begin{array}{l}\text { What are the important (characteristics) features/ } \\
\text { factors of the medical home model in this site? }\end{array}$} & 681 & $\begin{array}{l}\text { Care coordination/planned coordinated } \\
\text { care }\end{array}$ & $\mathrm{CC}$ \\
\hline & 663 & $\begin{array}{l}\text { Family-friendly materials and actions; } \\
\text { family participation }\end{array}$ & FCC \\
\hline & 422 & Teamwork, attitude & TBC \\
\hline & 252 & Care plan & $C C$, FCC \\
\hline & 247 & Community engagement and resources & $C C, F C C$ \\
\hline & 232 & $\begin{array}{l}\text { Focus on children with special health care } \\
\text { needs as population }\end{array}$ & QI \\
\hline & 226 & Access and communication about access & $C C$, FCC \\
\hline \multicolumn{4}{|l|}{ Key outcomes of becoming a medical homef; 800 (11) } \\
\hline \multirow{3}{*}{$\begin{array}{l}\text { Medical home outcomes/impact on staff and } \\
\text { patients/families? }\end{array}$} & 338 & Patient satisfaction & - \\
\hline & 267 & Quality of care & $\mathrm{FCC} / \mathrm{CC}$ \\
\hline & 182 & Clinician/staff satisfaction & - \\
\hline $\begin{array}{l}\text { a Out of } 7,302 \text { total items. } \\
\text { b Items aligned with attributes are labeled as follows: quality imp } \\
\text { ' Top } 3 \text { of } 6 \text { subdomains with the highest coding density are shor } \\
\text { d Top } 7 \text { of } 25 \text { subdomains are shown. } \\
\text { e Top } 7 \text { of } 16 \text { subdomains are shown. } \\
\text { f Top } 3 \text { of } 5 \text { highest-density items are shown. }\end{array}$ & vement (QI), family & centered care (FCC), team-based care (TBC), and car & coordination (CC). \\
\hline
\end{tabular}

coordination, and direct access to the team, have these. My eyes have been opened (physician champion, practice 10)

Clinicians and coordinators described an enhanced sense of professional satisfaction. The pediatric medical home became a special niche and more gratifying career path for them.

I love what I do, in part because of the medical home, I have more time with my patients; I earn less, but am happier (physician champion, practice 10 ).

It makes my life rich working with these kids; the medical home provides an innovative area of interest for me, a challenge, no condition scares me anymore-this is my new frontier (physician champion, practice 11).

Alternatively, supports for pediatric improvement were described as minimal and QI was described as strenuous. Physicians worried about inequitable levels of risk exposure as a consequence of caring for complex patients. They were disturbed about sustaining their mission while coping with practice standards demanding an unsupported level of quality. 2,19 There was concern that the pediatric medical home was being left behind in the midst of initiatives focused on cost savings for chronically ill adults. ${ }^{20-22}$ Operationally, medical home activities could be overwhelming and required the personal time of many nights and weekends.

Professional standards call us to meet quality indicators not supported by the payment system (physician champion, practice 4).

Leadership here is a volunteer activity (physician champion, practice 11). 


\section{Table 3. Primary Data Sources Analyzed Across Essential Medical Home Attributes}

\begin{tabular}{|c|c|c|c|}
\hline \multirow{2}{*}{$\begin{array}{l}\text { Essential Medical } \\
\text { Home Attribute }\end{array}$} & \multicolumn{3}{|c|}{ Primary Data Source } \\
\hline & $\overline{\mathrm{MHI}^{\mathrm{a}}}$ & Clinician Staff Questionnaire $^{b}$ & Semistructured Interviews \\
\hline Continuous QI & $\begin{array}{l}\text { MHI domain of QI was most improved } \\
\text { theme between precollaborative time } \\
\text { point (3.16) and current time point (5.79) }\end{array}$ & $\begin{array}{l}\text { AR mean score was } 0.75 \text {; of } \\
23 \text { AR items, } 12 \text { relate to QI } \\
\text { functions }\end{array}$ & $\begin{array}{l}\text { Interviews emphasized QI as ongo- } \\
\text { ing and enduring (rather than } \\
\text { rapid, time-limited transformation) }\end{array}$ \\
\hline FCC & $\begin{array}{l}\text { MHI question about "practice knowledge } \\
\text { and application" of FCC principles; } 100 \% \\
\text { of cohort knowledgeable and sometimes } \\
(25 \%) \text { or regularly }(75 \%) \text { apply FCC }\end{array}$ & $\begin{array}{l}\text { Mean score for CMHI question } \\
\text { on practice team "value of } \\
\text { family engagement" was } 0.80\end{array}$ & $\begin{array}{l}\text { Interviews emphasized value of fam- } \\
\text { ily involvement in the MHLC; this } \\
\text { emphasis continues today; practice } \\
\text { actions and materials emphasized } \\
\text { FCC }\end{array}$ \\
\hline $\begin{array}{l}\text { Team-based care/ } \\
\text { teamwork }\end{array}$ & $\begin{array}{l}\text { MHI scores converted to a } 100 \text {-point scale } \\
\text { improved overall between precollabora- } \\
\text { tive and current time points ( } 34 \%) \text {; con- } \\
\text { cept of "team" integrated across the } \mathrm{MHI}\end{array}$ & $\begin{array}{l}\text { AR mean score was } 0.75 ; \text { AR } \\
\text { is a measure of the team's } \\
\text { ability to make and sustain } \\
\text { changes }\end{array}$ & $\begin{array}{l}\text { Interviews highly emphasized team- } \\
\text { work and team attitude }\end{array}$ \\
\hline CC (team-based CC) & $\begin{array}{l}\text { MHI domain of CC improved between } \\
\text { precollaborative time point (3.82) and } \\
\text { current time point (6.39) }\end{array}$ & $\begin{array}{l}\text { AR mean score was } 0.75 ; \text { com- } \\
\text { bines and averages lead PCP } \\
\text { and CC scores (as key team } \\
\text { members) }\end{array}$ & $\begin{array}{l}\text { Interviews of highest emphasis } \\
\text { included quotes referencing CC, } \\
\text { teamwork, and attitude (of } 47 \% \\
\text { characteristic quotes } 50 \% \text { address) }\end{array}$ \\
\hline \multicolumn{4}{|c|}{$\begin{array}{l}\mathrm{AR}=\text { adaptive reserve; } \mathrm{CC}=\text { care coordination; } \mathrm{CMHI}=\text { Center for Medical Home Improvement; } \mathrm{FCC}=\text { family-centered care; } \mathrm{MHI}=\mathrm{Medical} \text { Home Index; } \\
\mathrm{MHLC}=\text { medical home learning collaborative; } \mathrm{PCP}=\text { primary care provider; } \mathrm{QI}=\text { quality improvement. }\end{array}$} \\
\hline \multicolumn{4}{|c|}{${ }^{a} \mathrm{MHI}$ scale ranged from 1 to 8 . Total MHI scores are expressed as a percentage of a maximum of 100.} \\
\hline
\end{tabular}

\section{Triangulated Results}

Table 3 shows results of the triangulation of the MHI and adaptive reserve to the dominant qualitative interview domains.

\section{DISCUSSION}

Data from this study suggest several important points relevant to factors that enable transformation, including 4 essential medical home attributes: (1) a culture of QI, (2) the delivery of family-centered care, (3) the value of team-based care, and (4) a focus on care coordination. ${ }^{14-16,23-25}$ Care quality and satisfaction were also evident.

Rapid medical home transformation, leading to a point-in-time metamorphosis, did not resonate with physician champions, parent partners, or care coordinators. Rather, a vigilant, ongoing process of familycentered QI resulting in continued transformation did resonate. The original learning collaborative was credited with initiating change but not completing it. Ongoing QI, family participation, teamwork, and care coordination were articulated and supported as necessary pediatric medical home attributes. Delivering care within a family-centered medical home proved highly satisfying to physicians and coordinators. As efforts expanded, professional gratification and staff resilience appeared linked. Family satisfaction was evident in interviews and surveys, contrasting with neutral findings in other demonstration evaluations. ${ }^{26}$

Today the medical home is promoted in pediatrics as a standard of quality care for all children. Our results reflect this shift. A former perspective of "our medical home children with special health care needs" is shifting to "our medical home system of care for all children and youth."

Care coordination was described as "probing, intense, detective work" helping families navigate the health care system. Lack of payment for care coordination was troubling and on each physician champion's mind.

Our results are similar in some respects to those of the Medical Home National Demonstration Project ${ }^{27}$ but more limited in resources and scope. Participants in that project described the importance of adaptive reserve, motivated team members, and positive impacts of facilitation on practice change. ${ }^{28,29}$ Ongoing facilitation was not available to our 12 teams. Both studies show almost identical levels of adaptive reserve. ${ }^{28}$ Alignment with medical home characteristics, variation of model element implementation, and evolving shifts of personal thinking about quality are similar. ${ }^{13}$ Larger system and policy supports for primary care are commonly stressed needs.

\section{Limitations}

Several factors must be considered when interpreting these results. Two of the authors (J.W.M., W.C.C.), as developers of the $\mathrm{MHI}$ and faculty members for the original learning collaboratives, may have introduced bias. The engagement of neutral researchers (J.V.C., A.A.B., and K.K.) in all aspects of study design may have mitigated this bias to some degree. The selection of high-performing practices allowed a focus on positive attributes associated with successful transformation. Information gleaned by studying less successful 
practices may have augmented our factors and allowed for comparison; such a study would be an important next step.

The practices we studied had multitalented teams and strong parent partners providing lessons perhaps not generalizable to practices nationally. Interviews targeted only the physician champion and care coordinator as informants, possibly limiting reports.

Finally, contextual factors undoubtedly influenced the study results and may affect the ability to transport the findings to other settings. These factors are summarized in the Supplemental Appendix (avail-

able online at http://ann

\section{Implications}

Our findings suggest that efforts to build and cultivate the pediatric medical home will benefit all children, their families, and clinicians alike, while enhancing care quality. Despite the above limitations and a potential need for broader study including more practices and staff, we feel ours is an important initial effort to identify critical transformative factors within pediatric primary care. Our results suggest that successful improvement toward the pediatric medical home model will require (1) QI supports with capabilities to drive change, (2) skill development to engage families as care and improvement partners, (3) competencies to ensure effective team-based, comprehensive care, (4) care coordination functionalities, and (5) payment aligned with the delivery of high-quality care.

To read or post commentaries in response to this article, see it online at http://www.annfammed.org/content/11/Suppl_1/S90.

Key words: change, organizational; children with special health care needs; disabled children; medical home; practice-based research; primary care; transformation

Submitted June 21, 2012; submitted, revised, January 25, 2013; accepted February 8, 2013.

Funding support: This work was supported by Agency for Healthcare Research and Quality (AHRQ) grant R18HS019157-01 and in part by the US Maternal and Child Health Bureau (USMCHB), Division for Children with Special Health Care Needs (CSHCN). The medical home learning collaborative described herein was funded under a cooperative agreement with the USMCHB CSHCN. Participation of each practice team was supported by their state Title V Program dedicated to the care of CSHCN. Additional funding support included NIMH grant K23MH083885 and NIMH grant R25MH080916.

Disclaimer: The authors of this article are responsible for its content. Statements in this presentation should not be construed as endorsements by the AHRQ or the US Department of Health and Human Services.

Acknowledgments: We would like to acknowledge the leadership, advice, guidance, and ongoing communication and coordination of the following 12 pediatric medical home practices: Saint Mary's Hospital - Children's Health Center, Waterbury, Connecticut; North Arlington Pediatrics, Illinois; Henry Ford Pediatrics, Detroit, Michigan; St Cloud CentraCare (Pediatrics), St Cloud, Minnesota; Chapel Hill Pediatrics and Adolescents, North Carolina; Prime Care Pediatrics, Zanesville, Ohio; Children's Hospital of Philadelphia Care Network, High Point, Pennsylvania; Lancaster General Health, Roseville Pediatrics, Pennsylvania; Su Clinica Familiar, Texas; Dr Robert Terashima's Practice, W Jordan, Utah; Pediatric Clinic at the University of Utah; and Intermountain Health Care/Budge Clinic/Pediatrics/Logan, Utah, as well as our study team members: Michelle Esquivel, MPH; Charles Homer, MD; Jennifer Lail, MD; Marilyn Peitso, MD; Sylvia Pelletier; Renee Turchi, MD; Vera Tait, MD; Robert S. Woodward, PhD, CMHI; and staff Lori Keehl Markowitz, BSN, and Leah Reed.

\section{References}

1. US Department of Health and Human Services. Health Resources and Services Administration (HRSA). Maternal and Child Health Bureau. Achieving \& Measuring Success: A National Agenda for Children with Special Health Care Needs. Rockville, MD: HRSA; 2005. http:// www.mchb.hrsa.gov/programs/specialneeds/achievingsuccess.html. Accessed June 1, 2012.

2. American Academy of Pediatrics Medical Home Program Advisory Committee. 2002 Policy Statement: The Medical Home. Pediatrics. 2002;113(5):1545-1547.

3. Devers K. The State of Quality Improvement Science in Health: What Do We Know About How to Provide Better Care? Washington, DC: Robert Wood Johnson Foundation Urban Institute; 2011. http:// www.urban.org/uploadedpdf/412454-State-of-Quality-ImprovementScience-in-Health.pdf. Accessed June 1, 2012.

4. Langley G, Nolan K, Nolan T, Norman L, Provost L. The Improvement Guide: A Practical Approach to Enhancing Organizational Performance. San Francisco, CA: Jossey-Bass; 1996.

5. Cooley WC, McAllister JW, Sherrieb K, Clark RE. The Medical Home Index: development and validation of a new practice-level measure of implementation of the Medical Home model. Ambul Pediatr. 2003;3(4):173-180.

6. Wagner EHAB, Austin BT, Davis C, Hindmarsh M, Schaefer J, Bonomi A. Improving chronic illness care: translating evidence into action. Health Aff (Millwood). 2001;20(6):64-78.

7. Homer CJ, Cooley WC, Kohrt A, Allen D, Gatto M. Using learning collaboratives to implement medical home in primary care. Paper presented at: CATCH and Medical Home National Conference; July 2004; Chicago, IL.

8. Bradley EH, Curry LA, Ramanadhan S, Rowe L, Nembhard IM, Krumholz HM. Research in action: using positive deviance to improve quality of health care. Implement Sci. 2009;4(25):25.

9. Agency for Healthcare Research and Quality. The CAHPS Database, Health Plans, 2011. Child Medicaid 4.0. Agency for Healthcare Research and Quality. 2011. http://www.cahps.ahrq.gov/CAHPSIDB/ Public/Topscores.aspx. Accessed Mar 31, 2012.

10. Centers for Disease Control and Prevention. Vital signs: asthma prevalence, disease characteristics, and self-management education. MMWR Morb Mortal Wkly Rep. 2011;60(17):547-52. http://www.cdc. gov/mmwr/preview/mmwrhtml/mm6017a4.htm.

11. Perrin EM, Flower KB, Ammerman AS. Body mass index charts: useful yet underused. J Pediatr. 2004;144(4):455-460.

12. Bethell C, Reuland C, Schor E, Abrahms M, Halfon N. Rates of parent-centered developmental screening: disparities and links to services access. Pediatrics. 2011;128(1):146-155.

13. Jaén $C R$, Crabtree BF, Palmer RF, et al. Methods for evaluating practice change toward a patient-centered medical home. Ann Fam Med. 2010;8(Suppl 1):S9-S20, S92. 
14. Cooley WC, McAllister JW. Building medical homes: improvement strategies in primary care for children with special health care needs. Pediatrics. 2004;113(5):1499-1506.

15. McAllister JW, Presler E, Cooley WC. Practice-based care coordination: a medical home essential. Pediatrics. 2007;120(3):e723-e733.

16. McAllister JW, Presler E, Turchi RM, Antonelli RC. Achieving effective care coordination in the medical home. Pediatr Ann. 2009;38(9):491-497. Erratum in Pediatr Ann. 2009;38(12):636. Turchi, Renee [corrected to Turchi, Renee M].

17. Kuhlthau KA, Bloom SR, Van Cleave J, et al. Evidence for familycentered care for children with special health care needs: a systematic review. Acad Pediatr. 2011;11(2):136-143.

18. Olsen W. Triangulation in Social Research: Qualitative and Quantitative Methods Can Really Be Mixed. Ormskirk, United Kingdom: Causeway Press; 2004.

19. American Academy of Pediatrics Committee on Children with Disabilities. Care Coordination in the Medical Home: Integrating Health and Related Systems of Care for Children with Special Health Care Needs. Pediatrics. 2005;116(5):1238-1244.

20. Berenson RA, Devers KJ, Burton RA. Will the Patient-Centered Medical Home Transform the Delivery of Health Care? Washington, DC: Robert Wood Johnson Foundation Urban Institute; 2011.

21. Dougherty D, Simpson LA. Measuring the quality of children's health care: a prerequisite to action. Pediatrics. 2004;113(1 Pt 2):185-198.

22. Wagner EH, Coleman K, Reid, R, Phillips, K, Sugarman, J. Guiding Transformation: How Medical Practices Can Become Patient-Centered Medical Homes. New York, NY: Commonwealth Fund; 2012.
23. Committee on Hospital Care. American Academy of Pediatrics. Family-centered care and the pediatrician's role. Pediatrics. 2003; 112(3 Pt 1):691-697.

24. Grumbach K, Bodenheimer T. Can health care teams improve primary care practice? JAMA. 2004;291(10):1246-1251.

25. Antonelli R, McAllister JW, Popp J. Making Care Coordination a Critical Component of the Pediatric Health System: A Multidisciplinary Framework. New York, NY: Commonwealth Fund; 2009.

26. Hoff T, Weller W, DePuccio M. The patient-centered medical home: a review of recent research. Med Care Res Rev. 2012;69(6):619-644.

27. Nutting PA, Miller WL, Crabtree BF, Jaén CR, Stewart EE, Stange KC. Initial lessons from the first national demonstration project on practice transformation to a patient-centered medical home. Ann Fam Med. 2009;7(3):254-260.

28. Nutting PA, Crabtree BF, Miller WL, Stewart EE, Stange $K C$, Jaén CR. Journey to the patient-centered medical home: a qualitative analysis of the experiences of practices in the National Demonstration Project. Ann Fam Med. 2010;8(Suppl 1):S45-S56, S92.

29. Nutting PA, Crabtree BF, Stewart EE, et al. Effect of facilitation on practice outcomes in the National Demonstration Project model of the patient-centered medical home. Ann Fam Med. 2010;8(Suppl 1): S33-S44, S92. 